\title{
Design Considerations for Chemotherapeutic Drug Nanocarriers
}

Rahul Misra ${ }^{1 *}$, Mohita Upadhyay ${ }^{2}$ and Sanat Mohanty ${ }^{1}$

${ }^{1}$ Advance Materials and NanoScience Laboratory, Department of Chemical Engineering, Indian Institute of Technology-Delhi, Hauz Khas, New Delhi, India ${ }^{2}$ Kusuma School of Biological Sciences, Indian Institute of Technology-Delhi, Hauz Khas, New Delhi, India

\begin{abstract}
The use of nanotechnology in delivering the chemotherapeutics drug has gained much attention recently. It is capable of killing the cancer much more effectively than any other method. The drug delivery systems using nanocarrier significantly enhances the efficacy of drug by improving the pharmacokinetics and the distribution of the drug to specific organs. For designing an effective nanocarrier, an insight of size, shape, surface chemistry and geometry is important. This review gives a map of guidelines for design of nanoparticle based chemotherapy. It reviews the mechanism of delivery in different pathways, physiology and chemistries involved and barriers to transport and delivery of nanocarrier based drugs, specifically for chemotherapeutic drugs. The microenvironment and physiology of a tumor site and its chemical environment is also reviewed, focusing on the impact on delivery. This review is an attempt to map the parameters that will help effective design of nanoparticles as drug carriers for chemotherapeutics. It discusses the accurate designing of nanocarriers as well as the effect of the environment to which a nanocarrier is exposed inside the body, its fate and uptake.
\end{abstract}

Keywords: Barriers; Chemotherapy; Drug delivery; Ligands; Nano medicine; Sustained release; Targeted; Surface functionality

\section{Introduction}

The drugs used in conventional chemotherapy targets both cancerous cells and non-cancerous cells. This makes the treatment of the cancer cells highly ineffective due to excessive toxicities [1]. Various attempts have been made to combat tumors specifically to spare non-cancerous cells [2]. But, cancer cells develop resistance to the conventional chemotherapeutics and the newer molecular approach thereby evading the cytotoxicity [3]. Due to several advantages, nanomedicines can be a promising approach for an effective and specific chemotherapy. Firstly, due to high surface to volume ratio, nanoscale carriers reduce the distribution volume of the drug [4,5], therefore improving the pharmacokinetics and the biodistribution of the drug to specific organs [6-9]. Secondly, specificity imposed to the nanocarriers

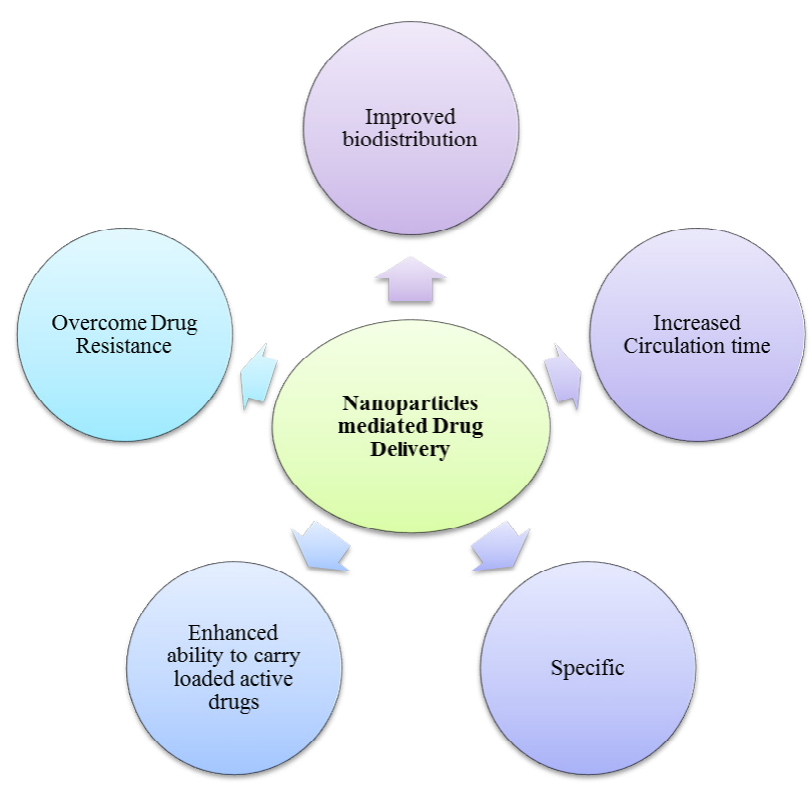

Figure 1: Advantages of Nanoparticles mediated drug delivery. lowers the cytotoxicity to healthy tissues [10]. Thirdly, easier delivery of hydrophobic drugs in parenteral mode [10-12]. Fourthly, the stability of several therapeutic drugs like peptides, hydrophobic compounds, etc. is found to increase using this delivery system [13-15]. Finally, safe nanocarriers due to biodegradable polymers due to lower side effects and better efficacy [16-18]. Figure 1 illustrates the different advantages offered by nanoparticles based drug delivery.

\section{Scope of the Review}

To design an effective nanocarrier, it is important to understand the environment in which a nanocarrier will travel its fate and challenges at different steps. Nanocarriers can only designed correctly with enough information about delivery pathway. Different pathways offer different challenges to a naoncarrier. These challenges can be overcome by considering all important factors responsible to its movement, functionality, recognition, specificity, etc. This review assesses all of these routes and environments to which the carrier is exposed and the barriers in each of these pathways. Moreover, this review acts as a guidelines and a map for the basic and essential parameters for designing nanocarriers for cancer therapy. This review will discuss all important factors for an effective nanocarrier design and help engineering the the nanoparticles in a way to achieve maximum uptake, minimum clearance by reticulo-endothelial system (RES), maximum transport in tumors and controlled release of drugs to constitute an efficient drug delivery system.

*Corresponding author: Rahul Misra, Advance Materials and NanoScience Laboratory, Department of Chemical Engineering, Indian Institute of Technology - Delhi, Hauz Khas, New Delhi 110016, India, Tel: +919582708534; E-mail: biotech.rahul.mishra@gmail.com

Received June 20, 2013; Accepted December 27, 2013; Published January 06 , 2014

Citation: Misra R, Upadhyay M, Mohanty S (2014) Design Considerations for Chemotherapeutic Drug Nanocarriers. Pharm Anal Acta 5: 279. doi: 10.4172/2153-2435.1000279

Copyright: (c) 2014 Misra R, et al. This is an open-access article distributed under the terms of the Creative Commons Attribution License, which permits unrestricted use, distribution, and reproduction in any medium, provided the original author and source are credited. 


\section{Drug Delivery Systems}

\section{Transdermal drug delivery system}

In this approach, the human skin is used as the primary route of administration of drugs into the bloodstream. Bioactive compounds are applied on to the skin to achieve therapeutic blood levels for treatment of diseases which are distant from the site of application. Human skin surface provides a surface area of approximately $2 \mathrm{~m}^{2}$ with $1 / 3^{\text {rd }}$ of blood supply of the body. It is one of the most conventional approaches for several decades. Drugs administered through this technique have to pass all the skin barriers and enter into the systemic circulation, which can be achieved by two ways:

i. Transcellular pathway, in which a drug passes through phospholipid membranes and the cytoplasm of the dead keratinocytes, which forms the outermost layer of epidermis (stratum corneum),

ii. Intercellular pathway, where a drug finds its way within the small spaces between the cells of the skin.

Despite being easiest mode of delivery, owing to convenience, absence of any complications (like those that affect delivery through gastrointestinal (GI) tract) and reduced side effects, this approach suffers from several disadvantages like local irritation, edema, low permeability of skin, uncontrolled release of drugs [18-21]. Barriers to transport of drugs through the skin limit the volume of drug that can be transported for successful administration of therapeutics.

\section{Parenteral drug delivery system}

Parenteral route of administration refers to injection, infusion or implantation of drug into the human or animal body. It can also be called as injectable drug delivery, which can be subcutaneous (SC/ SQ), intramuscular (IM) or intravascular (IV). Drugs with poor bioavailability and low therapeutic index can be delivered using this method. It has been reported that parenteral drug delivery market constitutes one of the largest segments and accounts for nearly $30 \%$ of the total market share. Immediate physiological response, improved bioavailability of drugs, the absence of GI tract complications (which includes drug-degradation), rapid and maximum absorption, flexibility are some of the major advantages for parenteral delivery system [2227]. Some major disadvantages are higher cost of manufacturing; invasive, aseptic conditions need to be followed. Trained healthcare professionals are required. These factors further add to the cost of this route for therapeutics delivery. In addition, there are other barriers. Drugs once injected cannot be removed from bloodstream. Patients feel pain or discomfort during injection, and this often results in poor patient compliance and acceptability especially if multiple daily injections required like in case of insulin, etc. [28,29].

\section{Transmucosal drug delivery system}

Transmucosal routes of delivery involve drug administration through mucosal linings of nasal, rectal, vaginal, ocular, and oral cavity. Mucosal linings are highly vascularized, have rich blood supply and good permeability. It provides several advantages over injectables and enteric routes. The major advantages of using mucosal route are the bypassing of GI tract and first-pass metabolism in liver. Drugs which are absorbed enter directly into the bloodstream and hence reducing the GI tract complications [29]. Due to high accessibility, oral mucosa has also been found to be the most acceptable route of administration.

The hurdles in therapeutics delivery using this route include high enzymatic environment of oral mucosa. The carrier / drug system needs to be permeable through barriers of oral mucosa. In some cases saliva (or other secretions) wash away the drug; there is a need for high mucoadhesion for effective delivery.

\section{Oral drug delivery system}

The oral route is considered to be the most widely accepted mode for drug delivery owing to the convenience, ease of administration and cost effectiveness $[29,30]$. This mode of administration of drug relies on the absorptive capacity of the gastrointestinal (GI) tract. The drug administered orally must overcome the acidic environment and enzymes present in GI tract. Hence, drug delivery vehicles are needed to increase the oral absorption, easy passage through intestinal membrane and avoid the destructive nature of GI tract [31]. This is accomplished with the use of nanotechnology which enables (i) the delivery of poorly water-soluble drugs, (ii) the targeting of drugs to the specific regions of the GI tract, (iii) transcytosis of drugs across the intestinal barriers, and (iv) intracellular delivery of drugs [32]. Use of nanomedicines is highly advantageous as apart from increasing the efficacy and tolerability of drug it provides wide range of nanosystems for oral drug delivery $[33,34]$. Nanocarriers ranging from polymeric nanoparticles, solid lipid nanoparticles, nanocrystals and self-nanoemulsifying systems have been applied for oral drug delivery [35].

\section{Targeted drug delivery}

Targeted drug delivery is the ability to direct any therapeutic agent to desired site of action specifically, with little or no interaction with non-target cells/tissues. "Clever" delivery system includes the parallel behavior of three components: the targeting moiety, the carrier and the therapeutic drug. Drug-targeting can be an (i) active strategy, which is also referred as receptor-ligand or ligand based targeting or the (ii) passive or physical targeting, which introduces the drug carrier complex into the body that can avoid elimination from body's defense mechanism, retains itself in circulation and reaches to the target site [36].

\section{Reticuloendothelial system (RES)}

The reticuloendothelial system (RES) is a physiological system involves in the elimination of foreign macromolecules and particles from the body. It is a part of the immune system that includes macrophages and monocytes. Such cells have the ability to take up particles and dyes through phagocytosis, a process involving the engulfment of solid particles by the cell membrane (also known as "cell eating"). RES functions to remove the dead cells from the circulation and to introduce phagocytic cells for inflammatory and immune responses. Different forms of drug carriers like liposomes, emulsions, nanocomposition, bilayer structures when administered intravenously are found to be restricted by the organs of RES (liver, spleen, bone marrow) [37-39].

\section{Tumor Microenvironment}

A detailed study of the tumor microenvironment is necessary for designing the effective delivery technique for chemotherapeutic drugs. Cancer cells exhibit a different microenvironment in comparison with the normal cells, such as, vascular abnormalities, oxygenation, perfusion, $\mathrm{pH}$ and metabolic states. Hence a better understanding of the tumor vasculature and interstitium help researchers to develop different therapeutic strategies. Tumor cells exhibit abnormalities in blood vessels, lymphatic system, vascular barrier, interstitium. Due to angiogenesis, growth of new cells occur from pre-existing ones which leads to highly dilated with wide interendothelial junctions, large 
number of fenestrations and transendothelial channels formed by vesicles, thick basement membrane, and leaky vessel walls with high permeability [40-44]. This abnormal growth helps tumors obtain extra oxygen and nutrients necessary for their growth and proliferation. All these abnormalities help molecules to transit across tumor vessels by phenomena called as enhanced permeation and retention effect (EPR) (Figure 2).

\section{Drug Nanocarriers}

Drug carriers are vehicles for protected transport of drugs to affected sites and their controlled release in the body. Therefore, the size and shape of the particles as well as their surface functionality should be manipulated in such manner which facilitates their transport through barriers of different membranes and tissues as well as the protection of the encapsulated drug during transport. Nanocarrier based drug delivery strategies leverage multiple aspects of nanoparticle structures: (i) nanomaterials provides large surface to volume ratio in

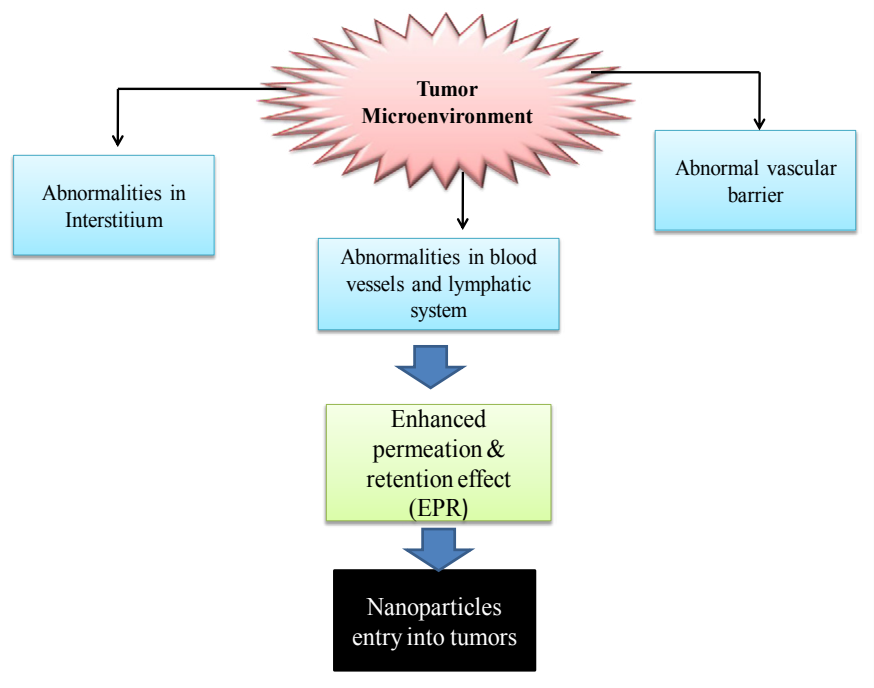

Figure 2: Diagrammatic representation of abnormalities in tumor microenvironment assisting the entry of nanopartciles in tumors.

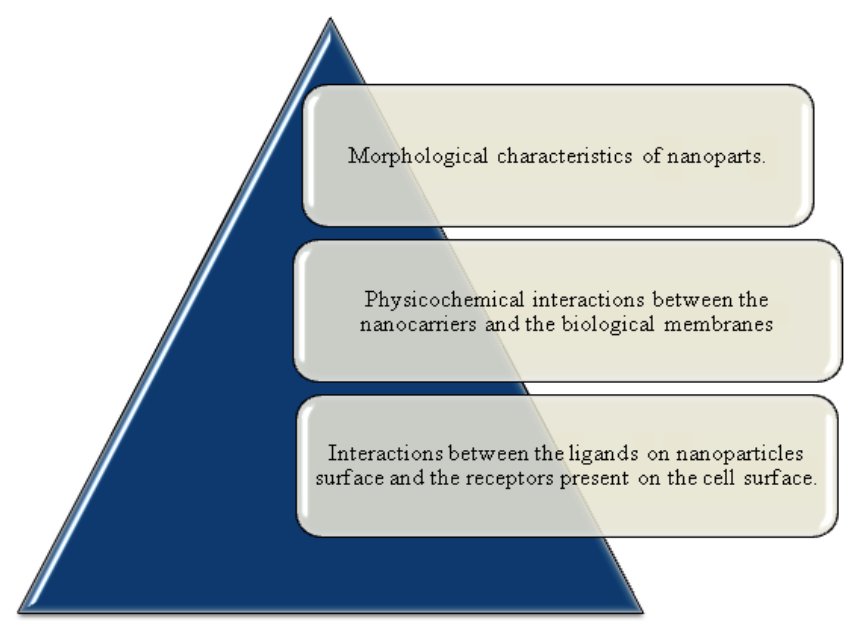

Figure 3: Flowchart for necessary information required while engineering the geometry of nanoparticle. comparison to other conventional drug vectors hence imparts them with properties like specificity, selectivity, versatility, etc.(ii) nanosize allows transportation of drugs through cells and membranes, and (iii) nanosize enables drugs to avoid RES. Dendrimers, polymeric micelles, polymeric nanoparticles, viral nanoparticles, liposomes are some the nanocarriers which have been used in the past for studying their applications in the field of cancer drug delivery.

\section{Design Parameters for Nanocarriers}

It is important to understand the interactions between the nanostructure and a biological membrane, before designing a nanocarrier. Past studies focussed on developing novel nanomaterials but the designing properties like nanostructures, size, shape, and surface chemistry did not get much attention For example, in delivery of any cancer drug to tumors, size, shape, surface charges and chemistry of nanocarrier influences delivery efficiency, and drug distribution. This insight can be used to redesign the nanomaterials accordingly so that large fraction of nanocarriers can penetrate and accumulate inside tumors. Moreover, it has been recently reported by Albanese et al. that even the interactions between the ligands on nanoparticles surface and the receptors present on the cell surface are also dependent on the engineered geometry of nanoparticle. Therefore, there are certain points (Figure 3) which should be kept in consideration while engineering the nanocarrier. Such as:

- It should escape clearance mechanism.

- It should be in circulation.

- It should escape opsonization.

- It should overcome drug resistance.

- It should have appropriate charge to adhere to the cell membrane.

- It should have proper ligands to bind with the receptors.

- It should be in a size small enough to escape phagocytosis and large enough to escape translocation in tissues and organs.

\section{Surface charge}

Nanoparticle properties for therapeutic applications are governed by several factors such size and shape, surface charge of the nanoparticles. One of the most important properties of nanoparticle to be controlled in the nanoparticle design is the cytotoxicity of nanoparticle. Charge density and charge polarity plays a major role in the cytotoxic action of a nanoparticle. Studies have shown that charged nanoparticles are more cytotoxic than neutral charged nanoparticles [44]. Among charged nanoparticles, positive forms are more cytotoxic than negatively charged nanoparticles [45-47]. The toxicity of poly (amidoamine) (PAMAM) dendrimers increases with an increase in number of amine groups [48]. However some nanoparticles such as $\mathrm{SiO}_{2}$ particles, porosity is a more important property than surface charge [49].

Cellular uptake of nanoparticle is also influenced by charge density. Cellular uptake involves electrostatic interactions between positively charged nanoparticle and membrane which favors its adhesion onto surface of cell. [50] On the other hand, even small but positively charged nanoparticle $(2 \mathrm{~nm})$ can alter the cell membrane potential as well as inhibits its proliferation and induces fluidity of the membrane [51]. Studies have shown that the uptake of charged polystyrene and iron oxide particles are better than their uncharged variants $[52,53]$. Cationic nanoparticles such as super paramagnetic iron oxide particles, 


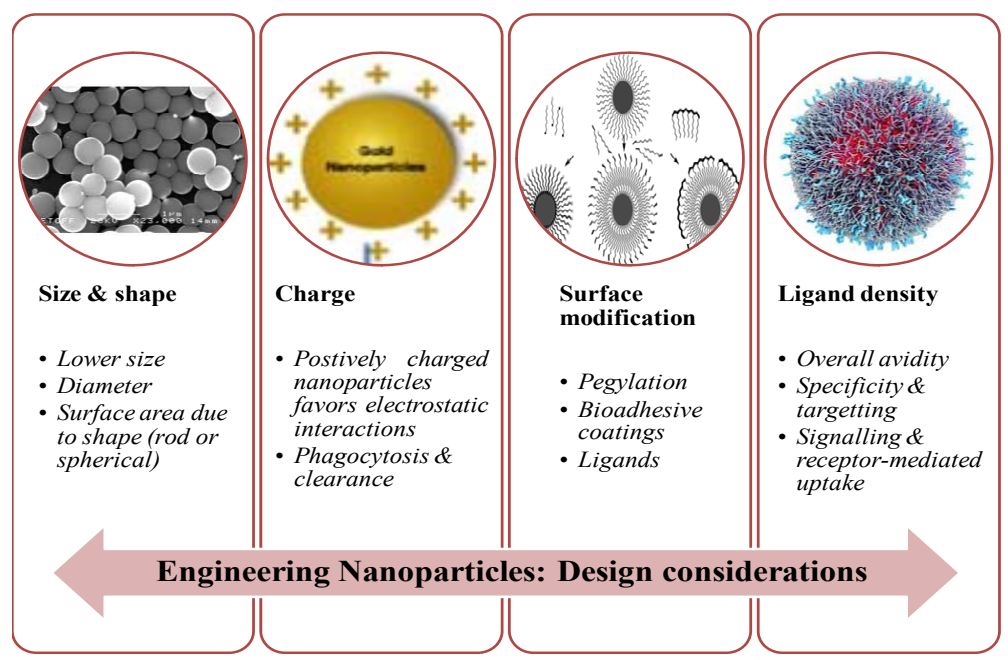

Figure 4: Represents different important parameters for engineering the geometry of a nanocarrier. These parameters are reviewed in detail in next sections.

lipid particles, poly (lactic acid), chitosan, gold and silver particles are taken up by the cells at a higher level than the anionic nanoparticles [5457]. However studies by Ryman-Rasmussen et al showed no difference in the uptake of cationic and anionic quantum dots [58] which was later contradicted by showing the difference of cellular uptake in positively charged and negatively charged quantum dots. High hydrophobicity of the negatively charged quantum dots attributed to its higher uptake by the cells than the positively charged and neutral quantum dots [59-70].

\section{Nanoparticle shape and geometry}

Apart from the various factors discussed, particle shape also contributes to the property of nanoparticles. Nanoparticle shape is a critical factor in drug delivery. There are several evidences that show the importance of particle shape on the release of drug. Studies have shown the controlled release of drugs is possible with the use of hemispherical sized particle, but not if the size of the particle is in the millimeter range [71]. Non-spherical particles show different rates of degradation because of different areas of thickness [72]. Geng et al. [73] found a positive correlation between in vivo blood circulation of nanoparticle and length-width ratio of the nanoparticle.

Transport of the nanoparticle will be greatly affected by the shape of the nanoparticle. Movement of the particle is dependent on the symmentry of the particle. Non-spherical particles may tumble when flowing through the organs such as liver and spleen or when the particles are encountered by the obstacles in the blood vessels [74].

Another factor governed by the particle shape is the targeting ability of the particle. Apart from the surface area of the particle, curvature, opsonin adsorption also affects the ligand targeting by the particle. Once the particles get attached to the contours of target plasma membrane, the protruding ends of particle are detached by the flow of blood. Thus, the protruding ends of the particle determine the longevity of the targeted attachment [75]. Particle shape not only determines the internalization of the targeted particles but also the transport and sorting of the particles once inside the cell [76].

Methods to fabricate non-spherical nanoparticle: Particle shape has not been investigated in detail particularly because of the limited methods available for the synthesis of non-spherical nanoparticle [75]. In recent years, several methods have been designed to fabricate the non-spherical nanoparticles, out of which the two main methods are: 1) synthesis of non-spherical nanoparticle from the beginning; 2) Alterations in the spherical particles fabricated earlier into nonspherical particle. Synthesis method involves the use of techniques such as lithography, microfluidics and photopolymerization [77,78].

The second method involves the manipulation of fabricated spherical particles into non-spherical particles. Studies have shown the formation of polystyrene sphere particles because of the self-assembled polystyrene spheres on the surface of a droplet [79]. Inspite of the advantages of the methods of fabrication of non-spherical nanoparticle, there are some limitations also. The most important limitation is the shape produced in the methods. For example, microfluidic methods generate two dimensional shapes and microchannel geometry is one of the limitations of this method [77] (Figure 4).

\section{Surface chemistry and modification}

Surface chemistry dictates the fate of a nanoparticle during clearance or uptake in circulation. It is essential for nanoparticles to have long circulation half life and to escape from macrophages (Figure 5). Therefore, residence time or circulation time is an important factor for effective designing of a nanocarrier. In cancer therapy, long circulation is required for passive targeting because EPR effect is observed in tumor vasculature after multiple passes [80-83]. But to achieve this, nanoparticles should be made such that drug degradation can be avoided. Therefore, surface modification is required to make the nanoparticle more effective in carrying the loaded drug to the targeted site. Nicholas et al. [84] reported that blood half-life of nanoparticles is dependent on the surfacehydrophobicity of nanoparticles. Nanoparticle's surface hydrophobicity determines the amount of proteins (opsonins) adsorbed on the surface. Particles which are more hydrophobic suffer more opsonization. Past studies have reported the PEG-ylation of the nanoparticles as hydrophilic blocks $[83,85,86]$. It increases the circulation time by escaping through immune cells (opsonisation). Past studies reported that PEG (Polyethylene glycol) prevents aggregation of the nanoparticles, helps in stabilising the nanoparticles, providing a neutral surface charge to nanoparticles, nanoparticles, escape from clearance by preventing from opsonins [87]. For effective modification of the surface, length and density of the PEG plays vital role $[88,89]$. PEG shields the inner core of nanoparticle from blood proteins by 


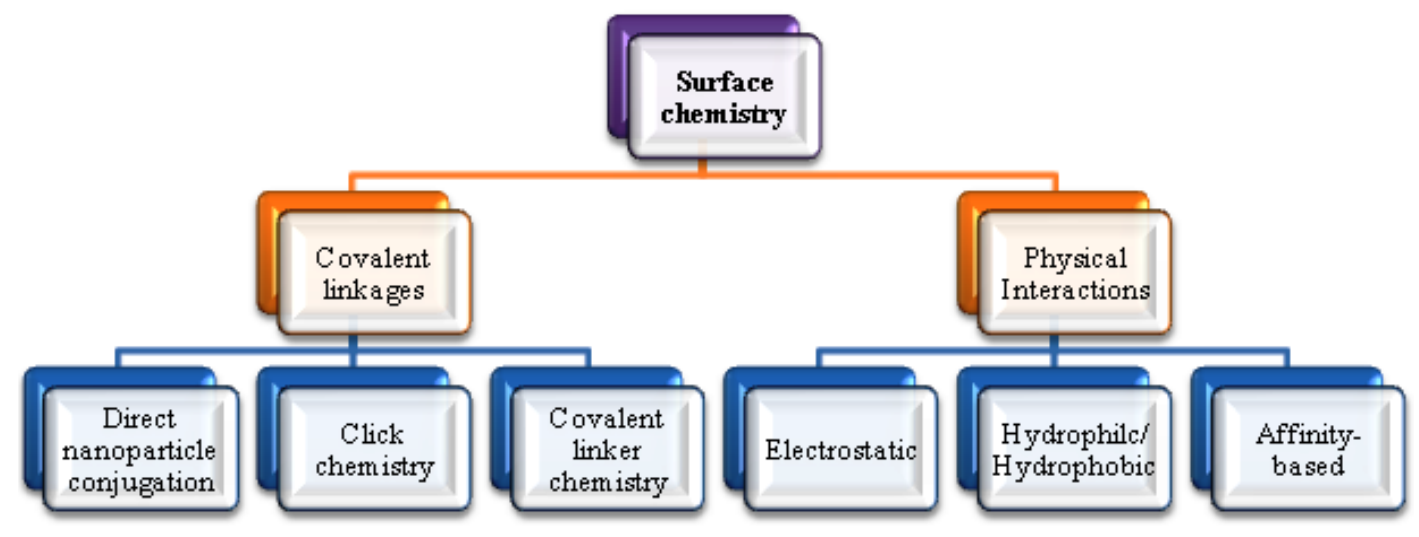

Figure 5: Methods for modification of nanocarrier's surface chemistry.

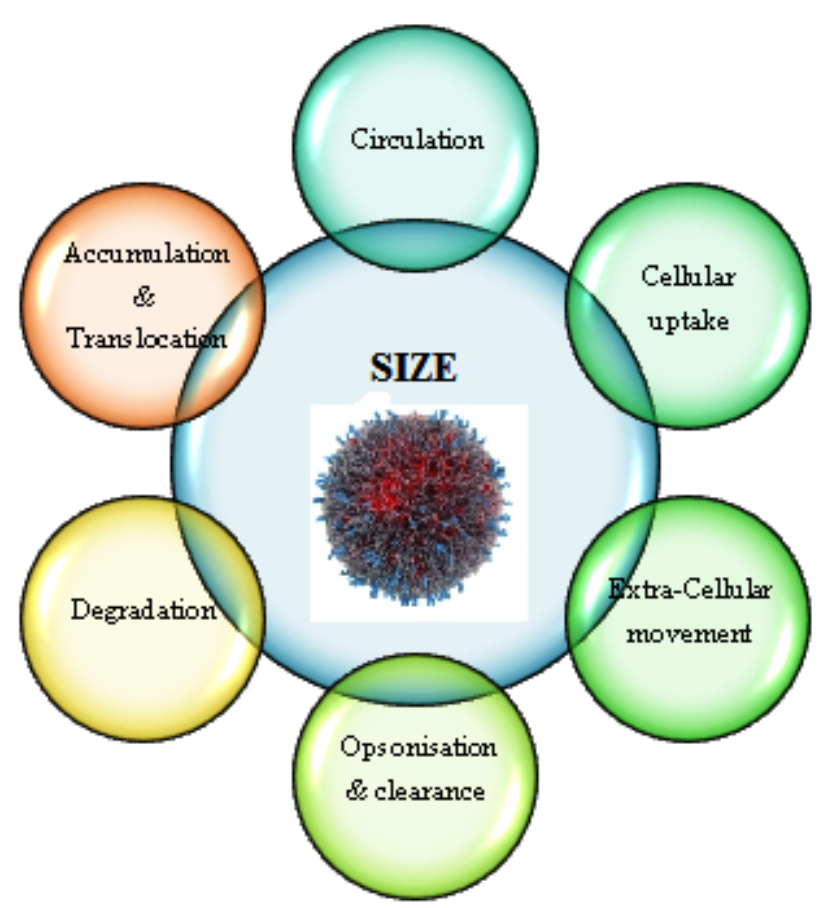

Figure 6: Influenec of size on nanoparticle mediated drug delivery.

forming a brush layer on the surface of nanoparticles. The access of encapsulated drug is restricted to the enzymes by modification of the nanoparticle surface therefore, improving pharmacokinetic profile and reducing non-specific toxicity [89-105].

Surface modification chemistry aims at specificity by targeting, ligand design, and is used in therapeutics, imaging reporter molecules [105-109].

\section{Effect of size}

Size of a particle influences the functionality of that particle like its uptake, residence in circulation, adherence, degradation as well as clearance [110-114] Size governs the movement of the nanoparticles inside the tissues. Figure 6 represents the effect of size on nanoparticles drug delivery. Champion et al. [75] reported that the movement of the particles inside tissues is dependent on the size as their movement can be sterically hindered in extra-cellular matrix. Based on the relationship between particle size and its curvature (for spheres), size of the nanoparticles along with surface chemistry, may also affect opsonization [115-121]. Recently, it was reported that [121] reported that size also play vital role in targeting nanoparticles accumulate inside the tumors by EPR effect, which in turn depends on the extravastion through the gaps in tumor vasculature. The ideal size range reviewed in past studies is $50-150 \mathrm{~nm}$. However, a study reports that ultra-small gold nanoparticles of size range $\leq 10 \mathrm{~nm}$ exhibits uniform distribution inside tumor tissues due to their ability to diffuse through tissues [122]. Fang et al. [123] carried out a study with PEG-PHDCA nanoparticles of size range $80-240 \mathrm{~nm}$ for cellular uptake and it was reported that smaller nanoparticles shown better circulation and accumulation but uptake was poor.

Particle diameter and size can be controlled by varying different 
physical and chemical parameters. Dunne et al. [117] have shown the effect of particle size on the degradation. There is no direct relationship between the initial degradation rate and size of the nanoparticles and microparticles. The size and diameter of a particle guides its way inside a bloodstream, diffusion in cells or membranes, air-passage or gastro-intestinal tract [124]. Size is an important factor to decide the destination and fate of the nanoparticles inside the body. Illum et al. [115] and Tabata and Ikada [116] reported the fate of the particles inside body. Tables 1-5 shows the effect of size and their fate inside of body.

Designing shape and size specific nanocarriers: Previous researches over several decades focused on designing of nanocarriers by two major approaches-bottom-up synthesis and top-down approach. Designing liposomal carriers, micelles, polymeric nanospheres, drug encapsulated polymeric nanoparticles are some vehicle which fall under "bottom up" category. This approach is based on self assembly and emulsion systems. Major advancement has been made recently in fabrication technology by introducing "top-down" approach in micro and nano-fabrication system using electromechanical approach (MEMS \& NEMS). They have exhibited the potential for designing nanoparticles with precision in particle shape and size. Such approach can provide control over particle size, functionality, particle geometry with accurate precision. This approach can also have ability to resolve the limitation of bottom-up approach.

Bottom-up synthesis: This approach has been extensively studied in past and several types of potential nanocarriers have been developed using this method for example, polymeric nanoparticles, micelles, liposomes, nanoemulsions, dendrimers, biodegaradble and nonbiodegradable carriers, solid lipid nanoparticles, magnetic nanoparticles etc. Each of these carriers has been extensively reviewed by various researchers in last decade. Several invitro and invivo studies have been

\begin{tabular}{|c|c|c|c|}
\hline Nanoparticle & Charge & Effects on Cell & References \\
\hline $\begin{array}{c}\text { Carbon } \\
\text { nanoparticles }\end{array}$ & Cationic & $\begin{array}{c}\text { Forms holes in plasma } \\
\text { membrane }\end{array}$ & {$[62]$} \\
\hline Quantum dots & Zwitterionic & $\begin{array}{c}\text { Increases the fluidity of plasma } \\
\text { membrane and causes swelling } \\
\text { of lysosomes }\end{array}$ & {$[63-64]$} \\
\hline Cationic & Neutral & $\begin{array}{c}\text { Forms holes in the plasma } \\
\text { membrane }\end{array}$ & {$[65]$} \\
\hline nilicon & Cationic & $\begin{array}{c}\text { Permealisation of lysosomes } \\
\text { aggregates }\end{array}$ & {$[67]$} \\
\hline TiO2 & - & Inhibits tubulin polymerization & {$[68]$} \\
\hline Cerium oxide & Cationic & Protein aggregation and & {$[69]$} \\
\hline Aluminium oxide & Zwitterionic & Disruption of tight junction & {$[70]$} \\
\hline
\end{tabular}

Table 1: Nanoparticle and cell interaction with different charged nanoparticles.

\begin{tabular}{|c|c|c|}
\hline $\begin{array}{c}\text { Coatings/ } \\
\text { Modifications }\end{array}$ & Advantages & References \\
\hline $\begin{array}{c}\text { Polyethylene glycol } \\
\text { (PEG) }\end{array}$ & $\begin{array}{c}\text { Neutral, escape RES, long circulation, } \\
\text { prevents degradation }\end{array}$ & {$[90-92]$} \\
\hline Dextran & Biocompatible and polar interactions & {$[93-95]$} \\
\hline Chitosan & $\begin{array}{c}\text { Easier functionalization, easily available, } \\
\text { biocompatible, cationic hydrophilic polymer }\end{array}$ & {$[96-97]$} \\
\hline $\begin{array}{c}\text { Polyethyleneimine } \\
\text { (PEI) }\end{array}$ & $\begin{array}{c}\text { Facilitates endosomal release by forming } \\
\text { complex with DNA }\end{array}$ & {$[98-100]$} \\
\hline $\begin{array}{c}\text { Liposomal \& } \\
\text { Micellar coatings }\end{array}$ & $\begin{array}{c}\text { Good encapsulation, sequestration and } \\
\text { protection of drugs inside body }\end{array}$ & {$[101]$} \\
\hline Co-polymers & Different functionalities of constituents & {$[102-103]$} \\
\hline
\end{tabular}

Table 2: Strategies for surface modification for nanoparticles.

\begin{tabular}{|c|c|c|}
\hline $\begin{array}{l}\text { Strategies in surface } \\
\text { chemistry }\end{array}$ & Details & References \\
\hline Nanoparticle conjugation & $\begin{array}{l}\text { - Functional groups directly } \\
\text { bonded to nanoparticle surface } \\
\text { or, } \\
\text { - Facilitated by catalyst. }\end{array}$ & [104] \\
\hline Click chemistry & $\begin{array}{l}\text { - Specific conjugation at desired } \\
\text { location (due to azide \& alkyne } \\
\text { reactive groups) } \\
\text { - Useful where orientation \& } \\
\text { stability of moiety is important. }\end{array}$ & [105] \\
\hline Linker chemistry & $\begin{array}{l}\text { Linker provides a control over } \\
\text { molecular orientation and useful for } \\
\text { controlled delivery systems }\end{array}$ & [106] \\
\hline Electrostatic interactions & Cationic-anionic interactions & [107] \\
\hline $\begin{array}{l}\text { Hydrophilic/hydrophobic } \\
\text { interactions }\end{array}$ & $\begin{array}{l}\text { Nanoparticle's surface engineered } \\
\text { with hydrophobic surface which can } \\
\text { adsorb hydrophobic drugs. }\end{array}$ & [106] \\
\hline Affinity interactions & $\begin{array}{l}\text { Surface modified with streptavidin for } \\
\text { specific bioconjugation. }\end{array}$ & [109] \\
\hline
\end{tabular}

Table 3: Different strategies reported for modification of surface chemistry of nanoparticle.

\begin{tabular}{|c|c|c|}
\hline Size range & Consequences & References \\
\hline$\geq 2 \mu \mathrm{m}$ & Trapped inside liver cells & 118,116 \\
\hline$\geq 200 \mathrm{~nm}$ & Filtered in spleen & 121 \\
\hline$\leq 100 \mathrm{~nm}$ & $\begin{array}{c}\text { Leave blood vessels through endothelial } \\
\text { linings }\end{array}$ & 116,122 \\
\hline$\geq 300-400 \mathrm{~nm}$ & $\begin{array}{c}\text { Captured by macrophages and excreted } \\
\text { out. }\end{array}$ & 116,119 \\
\hline $\begin{array}{c}\geq 3 \mu \mathrm{m} \text { (for pulmonary } \\
\text { administration) }\end{array}$ & $\begin{array}{c}\text { Accumulate in upper airways, smaller } \\
\text { exhaled out }\end{array}$ & 120 \\
\hline
\end{tabular}

Table 4: Size-based clearance mechanism.

\begin{tabular}{|c|c|c|}
\hline $\begin{array}{c}\text { Nanocarrier system } \\
\text { nolymeric microparticles \& } \\
\text { nanoparticles }\end{array}$ & Nanofabrication technique used & References \\
\hline PEGDA nanoparticles & S-FIL method & 147 \\
\hline Protein particles & PRINT & 145 \\
\hline Iron-oxide nanoparticles & PRINT & 149 \\
\hline Polymeric nanoparticles & $\begin{array}{c}\text { Polymeric coating (PEG) reduces } \\
\text { immunogenicity \& escape RES }\end{array}$ & $141-146$ \\
\hline Solid-lipid nanoparticles & $\begin{array}{c}\text { hydrophobic lipids that are solid } \\
\text { at room and body temperatures, } \\
\text { surrounded by a monolayer of } \\
\text { phospholipids }\end{array}$ & 148 \\
\hline Gold nanoparticles & $\begin{array}{c}\text { Real monitoring possible due to } \\
\text { optical properties }\end{array}$ & 149 \\
\hline
\end{tabular}

Table 5: Different types of nanocarrier developed using size specific strategies.

done and are still going on. Majority of these carriers are colloidal systems which are governed by different forces like hydrophobic interactions, vander-walls forces, hydrogen bonding, and ionic interactions. Often, high polydispersity have been exhibited by such system. Such systems sometimes undergo certain limitations. Invivo drug release profiles, physicochemical characteristics, degradation kinetics of these carriers are difficult to evaluate and reproduce as they are variable.

Top-down synthesis: Recent advancements in designing of nanoparticles have been made by micro- and nanofabrication techniques $[123,124]$. Different nano imprint lithography processes fall under this category (Figure 7). Today, advance researches in the field of nanofabrication for drug delivery are going on using soft lithography [125], thermal embossing [126-129], step and flash lithography [129,130], and UV embossing [131-133]. This technique has already been explored by Shvartsman and Desai et al. [134-136] at micron 


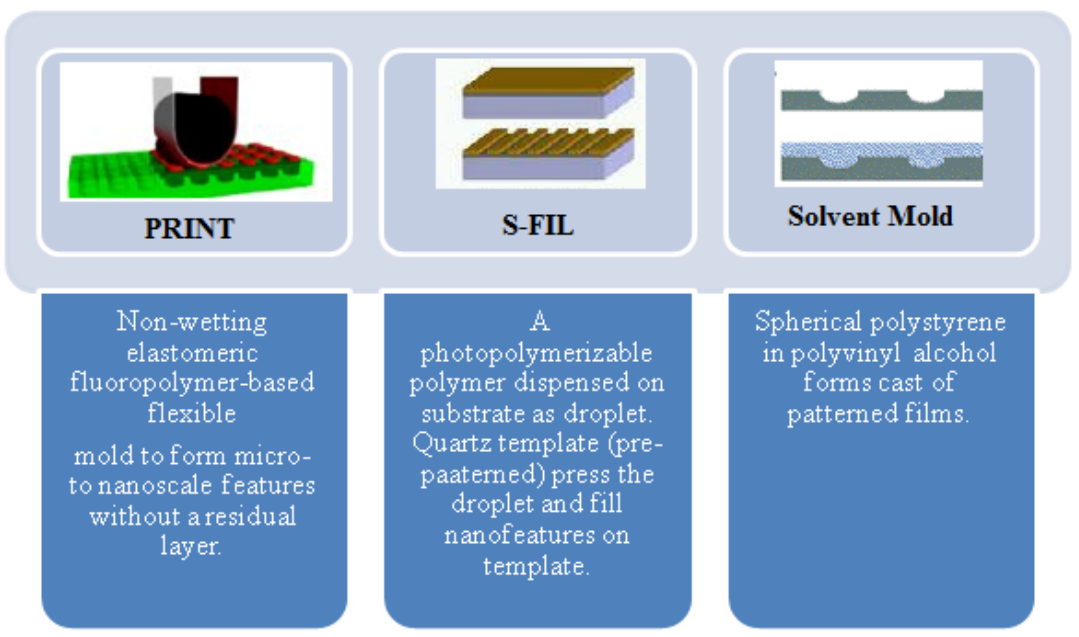

Figure 7: Techniques for designing a size \& shape specific nanocarrier.

scale explored for synthesizing biocapsules. Past studies have reported microfluidic devices for fabrication of shape specific microparticles [136-145]. In case of nanofabrication, nanoimprint lithography, step and flash imprint lithography (S-FIL), particle replication in nonwetting templates (PRINT) have gained much attention [145-149].

\section{Conclusion}

This review explains the parameters necessary for nanocarrier design to combat tumors. This review specifically focuses on challenges in a perfect nanocarrier development. There are conflicting effects of size or surface functionality in transport through membranes, blood stream and cellular uptake, for example, and this leads to a design sweet spot that allows for efficacious delivery. It describes the role of various aspects of the nanoparticle in supporting and enhancing drug delivery. This review develops a map for design of nanoparticle based chemotherapeutic strategies by recognizing the mechanisms of transport in the delivery pathway of choice, the barriers to these transport mechanisms, and the role of structure, functionality and material of nanoparticles in inhibiting or supporting transport.

\section{References}

1. Ross JS, Schenkein DP, Pietrusko R, Rolfe M, Linette GP, et al. (2004) Targeted therapies for cancer 2004. Am J Clin Pathol 122: 598-609.

2. Danhier F, Feron O, Préat $\vee(2010)$ To exploit the tumor microenvironment: Passive and active tumor targeting of nanocarriers for anti-cancer drug delivery. J Control Release 148: 135-146.

3. Morgillo F, Lee HY (2005) Resistance to epidermal growth factor receptortargeted therapy. Drug Resist Updat 8: 298-310.

4. Koo OM, Rubinstein I, Onyuksel H (2005) Role of nanotechnology in targeted drug delivery and imaging: a concise review. Nanomedicine 1: 193-212.

5. Drummond DC, Meyer O, Hong K, Kirpotin DB, Papahadjopoulos D (1999) Optimizing liposomes for delivery of chemotherapeutic agents to solid tumors. Pharmacol Rev 51: 691-743.

6. Au JL, Jang SH, Zheng J, Chen CT, Song S, et al. (2001) Determinants of drug delivery and transport to solid tumors. J Control Release 74: 31-46.

7. Fetterly GJ, Straubinger RM (2003) Pharmacokinetics of paclitaxel-containing liposomes in rats. AAPS PharmSci 5: E32.

8. Hoarau D, Delmas P, David S, Roux E, Leroux JC (2004) Novel long-circulating lipid nanocapsules. Pharm Res 21: 1783-1789.

9. Moghimi SM, Szebeni J (2003) Stealth liposomes and long circulating nanoparticles: critical issues in pharmacokinetics, opsonization and proteinbinding properties. Prog Lipid Res 42: 463-478.
10. Krishnadas A, Rubinstein I, Onyüksel H (2003) Sterically stabilized phospholipid mixed micelles: in vitro evaluation as a novel carrier for water-insoluble drugs. Pharm Res 20: 297-302.

11. Farokhzad OC, Langer $R$ (2009) Impact of nanotechnology on drug delivery. ACS Nano 3: 16-20.

12. Koo OM, Rubinstein I, Onyuksel H (2005) Camptothecin in sterically stabilized phospholipid micelles: a novel nanomedicine. Nanomedicine 1: 77-84.

13. Kristl J, Volk B, Gasperlin M, Sentjurc M, Jurkovic P (2003) Effect of colloidal carriers on ascorbyl palmitate stability. Eur J Pharm Sci 19: 181-189.

14. Arnedo A, Irache JM, Merodio M, Espuelas Millan MS (2004) Albumin nanoparticles improved the stability, nuclear accumulation and anticytomegaloviral activity of a phosphodiester oligonucleotide. J Control Release 94: 217-227.

15. Zhang JA, Anyarambhatla G, Ma L, Ugwu S, Xuan T, et al. (2005) Development and characterization of a novel Cremophor EL free liposome-based paclitaxel (LEP-ETU) formulation. Eur J Pharm Biopharm 59: 177-187.

16. Ibrahim NK, Desai N, Legha S, Soon-Shiong P, Theriault RL, et al. (2002) Phase $\mathrm{I}$ and pharmacokinetic study of ABI-007, a Cremophor-free, protein-stabilized, nanoparticle formulation of paclitaxel. Clin Cancer Res 8: 1038-1044.

17. Aungst BJ, Rogers NJ, Shefter E (1988) Comparison of nasal, rectal, buccal, sublingual and intramuscular insulin efficacy and the effects of a bile salt absorption promoter. J Pharmacol Exp Ther 244: 23-27.

18. Aungst BJ, Rogers NJ (1988) Site dependence of absorption-promoting actions of laureth-9, Na salicylate, Na2EDTA, and aprotinin on rectal, nasal, and buccal insulin delivery. Pharm Res 5: 305-308.

19. Lee WE (1990) Permeation enhancers for the nasal delivery of protein and peptide therapeutics. Bio Pharm 3:22-25.

20. Tengamnuay P, Mitra AK (1990) Bile salt-fatty acid mixed micelles as nasa absorption promoters of peptides. I. Effects of ionic strength, adjuvant composition, and lipid structure on the nasal absorption of [D-Arg2]kyotorphin Pharm Res 7: 127-133.

21. Cappel MJ, Kreuter J (1991) Effect of nanoparticles on transdermal drug delivery. J Microencapsul 8: 369-374.

22. Desai P, Patlolla RR, Singh M (2010) Interaction of nanoparticles and cellpenetrating peptides with skin for transdermal drug delivery. Mol Membr Biol 27: $247-259$

23. Ramadan S, Guo L, Li Y, Yan B, Lu W (2012) Hollow copper sulfide nanoparticlemediated transdermal drug delivery. Small 8: 3143-3150.

24. Shao Z, Mitra AK (1992) Nasal membrane and intracellular protein and enzyme release by bile salts and bile salt-fatty acid mixed micelles: correlation with facilitated drug transport. Pharm Res 9: 1184-1189.

25. Shao Z, Mitra AK (1994) Bile salt-fatty acid mixed micelles as nasal absorption promoters. III. Effects on nasal transport and enzymatic degradation of acyclovir prodrugs. Pharm Res 11: 243-250. 
26. Dal Negro R, Turco P, Pomari C, Trevisan F (1991) Calcitonin nasal spray in patients with chronic asthma: a double-blind crossover study vs placebo. Int $J$ Clin Pharmacol Ther Toxicol 29: 144-146.

27. Plosker GL, McTavish D (1996) Intranasal salcatonin (salmon calcitonin). A review of its pharmacological properties and role in the management of postmenopausal osteoporosis. Drugs Aging 8: 378-400

28. Reginster JY, Lecart MP (1995) Efficacy and safety of drugs for Paget's disease of bone. Bone 17: 485S-488S

29. Shojaei AH, Li X (1996) In vitro permeation of acyclovir through porcine buccal mucosa. Proceedings of 23rd International Symposium on Controlled Release of Bioactive Materials.

30. Schürmann W, Turner $P$ (1978) A membrane model of the human oral mucosa as derived from buccal absorption performance and physicochemical properties of the beta-blocking drugs atenolol and propranolol. J Pharm Pharmacol 30 $137-147$

31. Woodley J (2001) Bioadhesion: new possibilities for drug administration? Clin Pharmacokinet 40: 77-84.

32. Ugazio E, Cavalli R, Gasco MR (2002) Incorporation of cyclosporin A in solid lipid nanoparticles (SLN). Int J Pharm 241: 341-344.

33. Jenning V, Schäfer-Korting M, Gohla S (2000) Vitamin A-loaded solid lipid nanoparticles for topical use: drug release properties. J Control Release 66 115-126.

34. Zara GP, Cavalli R, Fundarò A, Bargoni A, Caputo O, et al. (1999) Pharmacokinetics of doxorubicin incorporated in solid lipid nanospheres (SLN). Pharmacol Res 40: 281-286.

35. zur Mühlen A, Schwarz C, Mehnert W (1998) Solid lipid nanoparticles (SLN) for controlled drug delivery--drug release and release mechanism. Eur J Pharm Biopharm 45: 149-155.

36. Zhang H, Zhang J, Streisand JB (2002) Oral mucosal drug delivery: clinical pharmacokinetics and therapeutic applications. Clin Pharmacokinet 41: 661 680

37. Tucker IG (1988) A method to study the kinetics of oral mucosal drug absorption from solutions. J Pharm Pharmacol 40: 679-683.

38. Barsuhn CL, Olanoff LS, Gleason DD, Adkins EL, Ho NF (1988) Human bucca absorption of flurbiprofen. Clin Pharmacol Ther 44: 225-231.

39. Gonzalez-Younes I, Wagner JG, Gaines DA, Ferry JJ, Hageman JM (1991) Absorption of flurbiprofen through human buccal mucosa. J Pharm Sci 80: 820823

40. Benes L, Brun J, Claustrat B, Degrande G, Ducloux N, Geoffriau M, et al (1993) Plasma melatonin (M) and sulfatoxymelatonin (aMT6s) kinetics afte transmucosal administration to humans Elsevier Science Publishers BV New York.

41. McQuinn RL, Kvam DC, Maser MJ, Miller AL, Oliver A (1995) Sustained ora mucosal delivery in human volunteers of buprenorphine from thin non-eroding mucoadhesive polymeric disks. J Control Rel 34: 243-250.

42. Bénès L, Claustrat B, Horrière F, Geoffriau M, Konsil J, et al. (1997) Transmucosal, oral controlled-release, and transdermal drug administration in human subjects: a crossover study with melatonin. J Pharm Sci 86: 1115-1119.

43. Hearnden V, Sankar V, Hull K, Juras DV, Greenberg M, et al. (2012) New developments and opportunities in oral mucosal drug delivery for local and systemic disease. Adv Drug Deliv Rev 64: 16-28.

44. Siegel IA, Gordon HP (1985) Surfactant-induced increases of permeability of rat oral mucosa to non-electrolytes in vivo. Arch Oral Biol 30: 43-47.

45. Manganaro AM, Wertz PW (1996) The effects of permeabilizers on the in vitro penetration of propranolol through porcine buccal epithelium. Mil Med 161: 669-672.

46. Schaeublin NM, Braydich-Stolle LK, Schrand AM, Miller JM, Hutchison J, et al (2011) Surface charge of gold nanoparticles mediates mechanism of toxicity. Nanoscale 3: 410-420.

47. Baek M, Kim IS, Yu J, Chung HE, Choy JH, et al. (2011) Effect of different forms of anionic nanoclays on cytotoxicity. J Nanosci Nanotechnol 11: 1803-1806.

48. Bhattacharjee S, de Haan LH, Evers NM, Jiang X, Marcelis AT, et al.(2010) Role of surface charge and oxidative stress in cytotoxicity of organic monolayercoated silicon nanoparticles towards macrophage NR8383 cells. Part Fibre Toxicol 7: 25 .
49. Goodman CM, McCusker CD, Yilmaz T, Rotello VM (2004) Toxicity of gold nanoparticles functionalized with cationic and anionic side chains. Bioconjug Chem 15: 897-900.

50. Chauhan AS, Diwan PV, Jain NK, Tomalia DA (2009) Unexpected in vivo anti-inflammatory activity observed for simple, surface functionalized poly(amidoamine) dendrimers. Biomacromolecules 10: 1195-1202.

51. Yu T, Malugin A, Ghandehari H (2011) Impact of silica nanoparticle design on cellular toxicity and hemolytic activity. ACS Nano 5: 5717-5728.

52. Misra R, Upadhyay M, Mohanty S (2013) Nanoparticles as Carriers for Chemotherapeutic Drugs: A Review. J Nanopharmaceutics Drug Delivery 1 : 103-137.

53. Zhang H, Oh M, Allen C, Kumacheva E (2004) Monodisperse chitosan nanoparticles for mucosal drug delivery. Biomacromolecules 5: 2461-2468.

54. Thorek DL, Tsourkas A (2008) Size, charge and concentration dependent uptake of iron oxide particles by non-phagocytic cells. Biomaterials 29: 35833590.

55. Villanueva A, Cañete M, Roca AG, Calero M, Veintemillas-Verdaguer S, et al (2009) The influence of surface functionalization on the enhanced internalization of magnetic nanoparticles in cancer cells. Nanotechnology 20: 115103.

56. Brandenberger C, Rothen-Rutishauser B, Mühlfeld C, Schmid O, Ferron GA et al. (2010) Effects and uptake of gold nanoparticles deposited at the air-liquid interface of a human epithelial airway model. Toxicol Appl Pharmacol 242: 56 65.

57. Cho J, Caruso F (2005) Investigation of the interactions between ligandstabilized gold nanoparticles and polyelectrolyte multilayer films. Chem Mater 17: 4547-4553.

58. Ge Y, Zhang Y, Xia J, Ma M, He S, et al. (2009) Effect of surface charge and agglomerate degree of magnetic iron oxide nanoparticles on KB cellular uptake in vitro. Colloids Surf B Biointerfaces 73: 294-301.

59. Yue ZG, Wei W, Lv PP, Yue H, Wang LY, et al. (2011) Surface charge affects cellular uptake and intracellular trafficking of chitosan-based nanoparticles. Biomacromolecules 12: 2440-2446.

60. Ryman-Rasmussen JP, Riviere JE, Monteiro-Riviere NA (2007) Surface coatings determine cytotoxicity and irritation potential of quantum do nanoparticles in epidermal keratinocytes. J Invest Dermatol 127: 143-153.

61. Bu Q, Yan G, Deng P, Peng F, Lin H, et al. (2010) NMR-based metabonomic study of the sub-acute toxicity of titanium dioxide nanoparticles in rats after oral administration. Nanotechnology 21: 125105

62. Panessa-Warren B, Warren J, Wong S, Misewich J (2006) Biological cellula response to carbon nanoparticle toxicity. J Phys Condens Matter. 18: S2185.

63. Wang T, Bai J, Jiang X, Nienhaus GU (2012) Cellular uptake of nanoparticles by membrane penetration: a study combining confocal microscopy with FTIR spectroelectrochemistry. ACS Nano 6: 1251-1259.

64. Funnell WR, Maysinger D (2006) Three-dimensional reconstruction of cell nuclei, internalized quantum dots and sites of lipid peroxidation. Nanobiotechnology 4: 10

65. Mecke A, Majoros IJ, Patri AK, Baker JR Jr, Holl MM, et al. (2005) Lipid bilayer disruption by polycationic polymers: the roles of size and chemical functional group. Langmuir 21: 10348-10354.

66. Mecke A, Uppuluri S, Sassanella TM, Lee DK, Ramamoorthy A, et al. (2004) Direct observation of lipid bilayer disruption by poly(amidoamine) dendrimers. Chem Phys Lipids 132: 3-14.

67. Thibodeau MS, Giardina C, Knecht DA, Helble J, Hubbard AK (2004) Silicainduced apoptosis in mouse alveolar macrophages is initiated by lysosomal enzyme activity. Toxicol Sci 80: 34-48.

68. Gheshlaghi ZN, Riazi GH, Ahmadian S, Ghafari M, Mahinpour R (2008) Toxicity and interaction of titanium dioxide nanoparticles with microtubule protein. Acta Biochim Biophys Sin (Shanghai) 40: 777-782.

69. Linse S, Cabaleiro-Lago C, Xue WF, Lynch I, Lindman S, et al. (2007) Nucleation of protein fibrillation by nanoparticles. Proc Natl Acad Sci U S A 104: 8691-8696.

70. Chen L, Yokel RA, Hennig B, Toborek M (2008) Manufactured aluminum oxide nanoparticles decrease expression of tight junction proteins in brain vasculature. J Neuroimmune Pharmacol 3: 286-295. 
71. Hsieh DS, Rhine WD, Langer R (1983) Zero-order controlled-release polymer matrices for micro- and macromolecules. J Pharm Sci 72: 17-22.

72. Panyam J, Dali MM, Sahoo SK, Ma W, Chakravarthi SS, et al. (2003) Polyme degradation and in vitro release of a model protein from poly $(\mathrm{D}, \mathrm{L}-$ lactide-coglycolide) nano- and microparticles. J Control Release 92: 173-187.

73. Geng Y, Dalhaimer P, Cai S, Tsai R, Tewari M, et al. (2007) Shape effects of filaments versus spherical particles in flow and drug delivery. Nat Nanotechnol 2: 249-255.

74. Moghimi SM, Hunter AC, Murray JC (2001) Long-circulating and target-specific nanoparticles: theory to practice. Pharmacol Rev 53: 283-318.

75. Champion JA, Katare YK, Mitragotri S (2007) Particle shape: a new design parameter for micro- and nanoscale drug delivery carriers. J Control Release 121: 3-9

76. Goode BL, Drubin DG, Barnes G (2000) Functional cooperation between the microtubule and actin cytoskeletons. Curr Opin Cell Biol 12: 63-71.

77. Xu S, Nie Z, Seo M, Lewis P, Kumacheva E, et al. (2005) Generation of monodisperse particles by using microfluidics: control over size, shape, and composition. Angew Chem Int Ed Engl 44: 724-728.

78. Dendukuri D, Pregibon DC, Collins J, Hatton TA, Doyle PS (2006) Continuousflow lithography for high-throughput microparticle synthesis. Nat Mater 5: 365 369.

79. Manoharan VN, Elsesser MT, Pine DJ (2003) Dense packing and symmetry in small clusters of microspheres. Science 301: 483-487.

80. Torchilin VP (2004) Targeted polymeric micelles for delivery of poorly soluble drugs. Cell Mol Life Sci 61: 2549-2559.

81. Khalid MN, Simard P, Hoarau D, Dragomir A, Leroux JC (2006) Long circulating poly(ethylene glycol)-decorated lipid nanocapsules deliver docetaxel to solid tumors. Pharm Res 23: 752-758.

82. Ho KS, Aman AM, Al-awar RS, Shoichet MS (2012) Amphiphilic micelles of poly(2-methyl-2-carboxytrimethylene carbonate-co-D,L-lactide)-graftpoly(ethylene glycol) for anti-cancer drug delivery to solid tumours. Biomaterials 33: $2223-2229$

83. Hall JB, Dobrovolskaia MA, Patri AK, McNeil SE (2007) Characterization of nanoparticles for therapeutics. Nanomedicine (Lond) 2: 789-803.

84. Nicholas AR, Scott MJ, Kennedy NI, Jones MN (2000) Effect of grafted polyethylene glycol (PEG) on the size, encapsulation efficiency and permeability of vesicles. Biochim Biophys Acta 1463: 167-178.

85. Photos PJ, Bacakova L, Discher B, Bates FS, Discher DE (2003) Polymer vesicles in vivo: correlations with PEG molecular weight. J Control Release 90: 323-334.

86. Tirosh O, Barenholz Y, Katzhendler J, Priev A (1998) Hydration of polyethylene glycol-grafted liposomes. Biophys J 74: 1371-1379.

87. Mahato RI (2005) Biomaterials for delivery and targeting of proteins and nucleic acids. CRC Press, Boca Ranton, Florida.

88. Fuertges F, Abuchowski A (1990) The Clinical efficacy of Poly(ethylene glycol)Modified Proteins. J Control Rel 11: 139-148.

89. Kim DK, Zhang Y, Kehr J, Klason T, Bjelke B, Muhammed M (2001) Characterization and MRI study of surfactant-coated superparamagnetic nanoparticles administered into the rat brain. Journal of Magnetism and Magnetic Materials 225: 256 -261.

90. Tiefenauer LX, Tschirky A, Kühne G, Andres RY (1996) In vivo evaluation of magnetite nanoparticles for use as a tumor contrast agent in MRI. Magn Reson Imaging 14: 391-402.

91. Tartaj P, Morales MP, Veintemillas-Verdaguer S, Gonzalez-Carreno T, Serna CJ (2006) Synthesis, properties and biomedical applications of magnetic nanoparticles. Handbook of Magnetic Materials16:403-482.

92. Weissleder R, Stark DD, Compton CC, Wittenberg J, Ferrucci JT (1987) Ferrite-enhanced MR imaging of hepatic lymphoma: an experimental study in rats. AJR Am J Roentgenol 149: 1161-1165.

93. Weissleder R, Hahn PF, Stark DD, Rummeny E, Saini S, et al. (1987) MR imaging of splenic metastases: ferrite-enhanced detection in rats. AJR Am J Roentgenol 149: 723-726.

94. Janes KA, Calvo P, Alonso MJ (2001) Polysaccharide colloidal particles as delivery systems for macromolecules. Adv Drug Deliv Rev 47: 83-97.
95. Kumar MN, Muzzarelli RA, Muzzarelli C, Sashiwa H, Domb AJ (2004) Chitosan chemistry and pharmaceutical perspectives. Chem Rev 104: 6017-6084.

96. Li BQ, Jia DC, Zhou Y, Hu QL, Cai W (2006) In situ hybridization to chitosan magnetite nanocomposite induced by the magnetic field. J Magnetism and Magnetic Materials 306: 223-227.

97. Kircheis R, Wightman L, Wagner E (2001) Design and gene delivery activity of modified polyethylenimines. Adv Drug Deliv Rev 53: 341-358.

98. Godbey WT, Wu KK, Mikos AG (1999) Tracking the intracellular path of poly(ethylenimine)/DNA complexes for gene delivery. Proc Natl Acad Sci U S A 96: 5177-5181.

99. Corti M, Lascialfari A, Marinone M, Masotti A, Micotti E, et al. (2008) Magnetic and relaxometric properties of polyethylenimine-coated superparamagnetic MRI contrast agents. Journal of Magnetism and Magnetic Materials 320: E316 - E319.

100. Mulder WJ, Strijkers GJ, van Tilborg GA, Griffioen AW, Nicolay K (2006) Lipidbased nanoparticles for contrast-enhanced MRI and molecular imaging. NMR Biomed 19: 142-164.

101. Veiseh O, Kievit FM, Gunn JW, Ratner BD, Zhang M (2009) A ligand-mediated nanovector for targeted gene delivery and transfection in cancer cells. Biomaterials 30: 649-657.

102. Kievit M, Veiseh O, Bhattarai N, Fang C, Gunn JW, et al. (2009) PEI-PEGChitosan-Copolymer-Coated iron oxide nanoparticles for safe gene delivery: synthesis, complexation, and transfection. Advanced Functional Materials 19 : $2244-2251$.

103. Weissleder R, Kelly K, Sun EY, Shtatland T, Josephson L (2005) Cell-specific targeting of nanoparticles by multivalent attachment of small molecules. Nat Biotechnol 23: 1418-1423.

104. von Maltzahn G, Ren Y, Park JH, Min DH, Kotamraju VR, et al. (2008) In vivo tumor cell targeting with "click" nanoparticles. Bioconjug Chem 19: 1570-1578.

105. Medarova Z, Pham W, Farrar C, Petkova V, Moore A (2007) In vivo imaging of siRNA delivery and silencing in tumors. Nat Med 13: 372-377.

106. Schellenberger E, Schnorr J, Reutelingsperger C, Ungethüm L, Meyer W, et al. (2008) Linking proteins with anionic nanoparticles via protamine: ultrasmall protein-coupled probes for magnetic resonance imaging of apoptosis. Smal 4: $225-230$

107. Jain TK, Richey J, Strand M, Leslie-Pelecky DL, Flask CA, et al. (2008) Magnetic nanoparticles with dual functional properties: drug delivery and magnetic resonance imaging. Biomaterials 29: 4012-4021.

108. Sinha R, Kim GJ, Nie S, Shin DM (2006) Nanotechnology in cancer therapeutics: bioconjugated nanoparticles for drug delivery. Mol Cancer The 5: 1909-1917.

109. Longmire M, Choyke PL, Kobayashi H (2008) Clearance properties of nanosized particles and molecules as imaging agents: considerations and caveats. Nanomedicine (Lond) 3: 703-717.

110. Begley DJ (2004) Delivery of therapeutic agents to the central nervous system: the problems and the possibilities. Pharmacol Ther 104: 29-45.

111. Bareford LM, Swaan PW (2007) Endocytic mechanisms for targeted drug delivery. Adv Drug Deliv Rev 59: 748-758.

112. Dobrovolskaia MA, Aggarwal P, Hall JB, McNeil SE (2008) Preclinical studies to understand nanoparticle interaction with the immune system and its potential effects on nanoparticle biodistribution. Mol Pharm 5: 487-495

113. Chouly C, Pouliquen D, Lucet I, Jeune JJ, Jallet P (1996) Development of superparamagnetic nanoparticles for MRI: effect of particle size, charge and surface nature on biodistribution. J Microencapsul 13: 245-255.

114. Toy R, Peiris PM, Ghaghada KB, Karathanasis E (2014) Shaping cance nanomedicine: the effect of particle shape on the in vivo journey of nanoparticles. Nanomedicine (Lond) 9: 121-134.

115. Illum L, Davis SS, Wilson CG, Thomas NW, Frier M, et al. (1982) Blood clearance and organ deposition of intravenously administered colloidal particles - the effects of particle-size, nature and shape. Int J Pharm 12:135 146.

116. Tabata Y, Ikada $Y(1990)$ Phagocytosis of polymer microspheres by macrophages. Adv Polym Sci 94: 107-141.

117. Dunne M, Corrigan I, Ramtoola Z (2000) Influence of particle size and dissolution conditions on the degradation properties of polylactide-co-glycolide particles. Biomaterials 21: 1659-1668. 
Citation: Misra R, Upadhyay M, Mohanty S (2014) Design Considerations for Chemotherapeutic Drug Nanocarriers. Pharm Anal Acta 5: 279. doi: $10.4172 / 2153-2435.1000279$

118. Stolnik S, Illum L, Davis SS (1995) Long circulating microparticulate drug carriers. Adv Drug Deliv Rev 16: 195-214.

119. Rejman J, Oberle V, Zuhorn IS, Hoekstra D (2004) Size-dependent internalization of particles via the pathways of clathrin- and caveolae-mediated endocytosis. Biochem J 377: 159-169.

120. May RC, Machesky LM (2001) Phagocytosis and the actin cytoskeleton. J Cell Sci 114: 1061-1077.

121.Karyn S Ho, Molly S (2013) Shoiche Design considerations of polymeric nanoparticle micelles for Chemotherapeutic delivery. Current Opinion in Chemical Engineering 2: 53-59.

122. Huang K, Ma H, Liu J, Huo S, Kumar A, et al. (2012) Size-dependent localization and penetration of ultrasmall gold nanoparticles in cancer cells, multicellular spheroids, and tumors in vivo. ACS Nano 6: 4483-4493.

123. Fang C, Shi B, Pei YY, Hong MH, Wu J, et al. (2006) In vivo tumor targeting of tumor necrosis factor-alpha-loaded stealth nanoparticles: effect of MePEG molecular weight and particle size. Eur J Pharm Sci 27: 27-36.

124. Xia Y, Whitesides GM (1998) Soft Lithography. Angew Chem Int Ed 37: 550575.

125. Resnick DJ, Sreenivasan SV, Wilson CG (2005) Step and flash imprint lithography. Materials today: 34-42.

126. Koh WG1, Revzin A, Pishko MV (2002) Poly(ethylene glycol) hydrogel microstructures encapsulating living cells. Langmuir 18: 2459-2462.

127. Stephen YC, Peter RK, Zhang W (1997) Sub - $10 \mathrm{~nm}$ imprint lithography and applications. J Vac Sci Technol B 15: 2897-2904.

128. Chou SY, Krauss PR, Renstrom PJ (1996) Imprint Lithography with 25-Nanometer Resolution. Science. 272: 85-87.

129. Bacher W, Bade K, Matthis B (1998) Fabrication of LIGA mold inserts. Microsystem Technologies. 4: 117-119.

130. Matthew C, Annette G, Byung Jin C (2001) Patterning nonflat substrates with a low pressure, room temperature, imprint lithography process. J Vac Sci Technol B 19: 2162-2172.

131. Jan H, Martin V, Kees van den $H$ (1996) Mold-assisted nanolithography: A process for reliable pattern replication. AVS 4124-4128.

132. Bender M, Otto M, Hadam B (2000) Fabrication of nanostructures using a UVbased imprint technique. Microelectronic Engineering, 53: 233-236.

133. Gale MT (1997) Replication techniques for diffractive optical elements. Microelectronic Engineering 34: 321-339.

134.Shvartsman FP (1991) Holographic optical elements by dry photopolyme embossing. SPIE 1461: 313-320.

135. Desai TA, Chu WH, Tu JK, Beattie GM, Hayek A, et al. (1998) Microfabricated immunoisolating biocapsules. Biotechnol Bioeng 57: 118-120.
136. Desai TA, Hansford DJ, Kulinsky L, Nashat AH, Rasi G, et al. (1999) Nanopore Technology for Biomedical Applications. Biomed Microdev 2: 11-40.

137. Dendukuri D, Hatton TA, Doyle PS (2007) Synthesis and self-assembly of amphiphilic polymeric microparticles. Langmuir 23: 4669-4674.

138. Dendukuri D, Tsoi K, Hatton TA, Doyle PS (2005) Controlled synthesis of nonspherical microparticles using microfluidics. Langmuir 21: 2113-2116.

139. Ganesan R, Dumond J, Saifullah MS, Lim SH, Hussain H, et al. (2012) Direct patterning of TiOâ,, using step-and-flash imprint lithography. ACS Nano 6 : 1494-1502.

140.korn ED, Remy CN, Wasilejko HC, Buchanan JM (1955) Biosynthesis of the purines. VII. Synthesis of nucleotides from bases by partially purified enzymes. J Biol Chem 217: 875-883.

141. Glangchai LC, Caldorera-Moore M, Shi L, Roy K (2008) Nanoimprint lithography based fabrication of shape-specific, enzymatically-triggered smart nanoparticles. J Control Release 125: 263-272.

142. Kelly JY, DeSimone JM (2008) Shape-specific, monodisperse nano-molding of protein particles. J Am Chem Soc 130: 5438-5439.

143. Tominaga M, Miyahara K, Soejima K, Nomura S, Matsumoto $M$, et al (2007) Size-tuneable and micro-patterned iron nanoparticles derived from biomolecules via microcontact printing SAM-modified substrates and controlled-potential electrolyses. J Colloid Interface Sci 313: 135-140.

144. Gratton SE, Pohlhaus PD, Lee J, Guo J, Cho MJ, et al. (2007) Nanofabricated particles for engineered drug therapies: a preliminary biodistribution study of PRINT nanoparticles. J Control Release 121: 10-18.

145. Caldorera-Moore M, Guimard N, Shi L, Roy K (2010) Designer nanoparticles: incorporating size, shape and triggered release into nanoscale drug carriers Expert Opin Drug Deliv 7: 479-495.

146. Alyautdin RN, Petrov, VE, Langer K, Berthold A, Kharkevich DA, et al. (1997) Delivery of loperamide across the blood-brain barrier with polysorbate 80-coated polybutylcyanoacrylate nanoparticles. Pharm Res14: 325-328.

147. Alyaudtin RN, Reichel A, Löbenberg R, Ramge P, Kreuter J, et al. (2001) Interaction of poly(butylcyanoacrylate) nanoparticles with the blood-brain barrier in vivo and in vitro. J Drug Target 9: 209-221.

148. Dasgupta S, Ghosh SK, Ray S, Mazumder B (2013) Solid Lipid Nanoparticles (SLNs) Gels for Topical Delivery of Aceclofenac in vitro and in vivo Evaluation. Curr Drug Deliv 10: 656-666.

149.Probst CE, Zrazhevskiy P, Bagalkot V, Gao X (2013) Quantum dots as a platform for nanoparticle drug delivery vehicle design. Adv Drug Deliv Rev 65: 703-718. 